\title{
REVIEW
}

\section{The emerging role of the fibroblast growth factor-23-klotho axis in renal regulation of phosphate homeostasis}

\author{
Mohammed S Razzaque and Beate Lanske \\ Department of Developmental Biology, Harvard School of Dental Medicine, Research and Education Building, Room \# 304, 190 Longwood Avenue, Boston, \\ Massachusetts 02115, USA \\ (Requests for offprints should be addressed to M S Razzaque; Email: mrazzaque@hms.harvard.edu)
}

\begin{abstract}
Normal mineral ion homeostasis is tightly controlled by numerous endocrine factors that coordinately exert effects on intestine, kidney, and bone to maintain physiological balance. The importance of the fibroblast growth factor (FGF)-23klotho axis in regulating mineral ion homeostasis has been proposed from recent research observations. Experimental studies suggest that 1) FGF23 is an important in vivo regulator of phosphate homeostasis, 2) FGF23 acts as a counter regulatory hormone to modulate the renal $1 \alpha$-hydroxylase and sodium-phosphate cotransporter activities, 3 ) there is a trend of interrelationship between FGF23 and parathyroid

hormone activities, 4) most of the FGF23 functions are conducted through the activation of FGF receptors, and 5) such receptor activation needs klotho, as a cofactor to generate downstream signaling events. These observations clearly suggest the emerging roles of the FGF23-klotho axis in maintaining mineral ion homeostasis. In this brief article, we will summarize how the FGF23-klotho axis might coordinately regulate normal mineral ion homeostasis, and how their abnormal regulation could severely disrupt such homeostasis to induce disease pathology.

Journal of Endocrinology (2007) 194, 1-10
\end{abstract}

\section{Introduction}

Maintaining physiological phosphate balance is of crucial biological importance, as it regulates various biological processes, as well as skeletal mineralization; it is an important component of nucleic acids, signaling proteins, coenzymes, and lipid bilayer of the cell membranes. Acute hypophosphatemia can cause myopathy, cardiac dysfunction, and hematological abnormalities; while chronic hypophosphatemia mostly affects bone mineralization to develop rickets and osteomalacia. On the other hand, hyperphosphatemia is associated with secondary hyperparathyroidism, commonly present in patients with chronic kidney diseases (CKDs). Understanding the molecular regulation of phosphate homeostasis is, therefore, of enormous clinical and biological importance. In an average healthy $70 \mathrm{~kg}$ adult individual, the total body phosphorus content is around $700 \mathrm{~g}$, almost $80 \%$ of which is present in the skeleton as crystalline hydroxyapatite $\left(\mathrm{Ca}_{10}\left(\mathrm{PO}_{4}\right)_{6}(\mathrm{OH})_{2}\right)$, about $9 \%$ in the skeletal muscle, roughly $10.9 \%$ in the viscera, and the remaining $0 \cdot 1 \%$ in the extracellular fluid (Gaasbeek \& Meinders 2005). Intracellular phosphates are mostly present as organic phosphate compounds, such as creatine phosphate and ATPs; intracellular phosphate stores are also found in red cells as 2,3-diphosphoglycerate, which partly controls the $\mathrm{O}_{2}$ release to tissues by hemoglobin in red cells. Roughly $70 \%$ of the phosphate is absorbed in the duodenum and jejunum, through a sodium-dependent active transport, a process stimulated by 1,25-dihydroxyvitamin $\mathrm{D}_{3}\left(1,25(\mathrm{OH})_{2} \mathrm{D}\right)$; moreover, parathyroid hormone (PTH) and low-phosphate diets can stimulate intestinal absorption of phosphate by exerting effects on vitamin D. For instance, hypophosphatemia can stimulate activity of the renal $1 \alpha$-hydroxylase $(1 \alpha(\mathrm{OH})$ ase $)$ to increase the synthesis of $1,25(\mathrm{OH})_{2} \mathrm{D}$.

The kidney is one of the most important sites for physiologic regulation of serum phosphate; it controls urinary phosphate excretion to balance the intestinal phosphate absorption. About $85 \%$ of renal reabsorption of phosphate occurs in the proximal tubules. Phosphate from the tubular lumen moves across the proximal tubular epithelial cells and effluxes at the basolateral membrane. Phosphate transport across the proximal tubular epithelial cells is a sodiumdependent process, and driven by a higher extracellular sodium gradient compared with inside the cell, and such a gradient is believed to be maintained by the basolateral membrane-associated Na,K-ATPase. Sodium/phosphate $(\mathrm{Na} / \mathrm{Pi})$ cotransporter-mediated phosphate uptake across the 
brush-border membrane is an electrogenic process and has pH sensitivity (Tenenhouse 2005). Although the precise mechanisms involved in the translocation of phosphate across the proximal tubular epithelial cells, and the efflux of phosphate across the basolateral membrane to the blood vessels are not yet clear, our understanding of the $\mathrm{Na} / \mathrm{Pi}$ cotransporter system has significantly enhanced our knowledge of renal regulation of phosphate homeostasis.

\section{Renal regulation of phosphate homeostasis}

Renal regulation of phosphate homeostasis is a complex process and is influenced by numerous intrinsic and extrinsic factors. For instance, factors that increase renal phosphate reabsorption include phosphate depletion, parathyroidectomy, $1,25(\mathrm{OH})_{2} \mathrm{D}$, hypocalcemia, and hypocapnia; in contrast, factors that inhibit renal phosphate reabsorption include phosphate loading, PTH, volume expansion, hypercalcemia, carbonic anhydrase inhibitors, fibroblast growth factor (FGF)-7, FGF23, frizzledrelated protein-4, and matrix extracellular phosphoglycoprotein. Many of these factors exert either stimulatory or inhibitory effects on renal $\mathrm{Na}$ / $\mathrm{Pi}$ cotransporters to positively or negatively regulate phosphate balance.

The $\mathrm{Na} / \mathrm{Pi}$ cotransporter family mainly consists of three different types. Type I Na/Pi cotransporters are mostly present in the brush-border membrane of proximal tubular cells (Biber et al. 1993); subsequent studies, however, suggest that type $1 \mathrm{Na} / \mathrm{Pi}$ is not a typical cotransporter, rather influences intrinsic cellular phosphate transport (Soumounou et al. 2001). Type II Na/Pi cotransporters have three highly homologous isoforms; type IIa (Na/Pi-2a) and type IIc $(\mathrm{Na} / \mathrm{Pi}-2 \mathrm{c})$, which are almost exclusively present in the brush-border membrane of the renal proximal tubular epithelial cells (Custer et al. 1994, Segawa et al. 2002). In contrast, type $\mathrm{IIb}(\mathrm{Na} / \mathrm{Pi}-2 \mathrm{~b})$ cotransporters are present in the small intestinal lining epithelial cells, and are thought to be involved in intestinal phosphate absorption; of relevance, $\mathrm{Na} / \mathrm{Pi}-2 \mathrm{~b}$ cotransporters are not expressed in the kidney (Hilfiker et al. 1998). The third type of cotransporters, type III $\mathrm{Na} / \mathrm{Pi}$, are ubiquitously expressed (Kavanaugh et al. 1994), and present in the basolateral membrane of the renal tubules, where they are thought to serve a housekeeping function. Both $\mathrm{Na} / \mathrm{Pi}-2 \mathrm{a}$ and $\mathrm{Na} / \mathrm{Pi}-2 \mathrm{c}$ regulate renal phosphate transport in a sodium-dependent process; $\mathrm{Na} / \mathrm{Pi}-2 \mathrm{a}-$ mediated transport is an electrogenic process, where membrane voltage acts as a kinetic determinant of inward fluxing of three sodium ions along with one divalent phosphorus anion (Forster et al. 2006). The intestinal $\mathrm{Na} / \mathrm{Pi}-2 \mathrm{~b}$ cotransporters are also electrogenic, while the $\mathrm{Na} / \mathrm{Pi}-2 \mathrm{c}$ isoform mediates the electroneutral transport of two sodium ions with one divalent phosphorus anion. Since phosphate transport through the $\mathrm{Na} / \mathrm{Pi}$ cotransporter system is the main regulatory mechanism of maintaining phosphate balance, the molecules that directly or indirectly affect the $\mathrm{Na} / \mathrm{Pi}$ cotransporter system could, therefore, influence phosphate homeostasis.

There are numerous factors that affect phosphate transport by exerting effects on the $\mathrm{Na} / \mathrm{Pi}$ cotransporter system, one of the molecules that is widely studied is PTH. PTH could inhibit the $\mathrm{Na} / \mathrm{Pi}$ cotransporter system across the brushborder membrane by endocytic retrieval of $\mathrm{Na} / \mathrm{Pi}-2 \mathrm{a}$ and $\mathrm{Na} / \mathrm{Pi}-2 \mathrm{c}$ proteins from the brush-border membrane to the subapical compartment; the internalized $\mathrm{Na} / \mathrm{Pi}$ proteins are eventually degraded in lysosomes (Tenenhouse 2005, Forster et al. 2006). In contrast, phosphate deprivation is associated with microtubule-dependent recruitment of $\mathrm{Na} / \mathrm{Pi}-2 \mathrm{a}$ and $\mathrm{Na} / \mathrm{Pi}-2 \mathrm{c}$ proteins to the apical membrane (Tenenhouse 2005, Forster et al. 2006). The retrieval and recruitment of $\mathrm{Na} / \mathrm{Pi}-2 \mathrm{a}$ and $\mathrm{Na} / \mathrm{Pi}-2 \mathrm{c}$ proteins are a complex multi-step multifactorial process, and needs additional study for comprehensive understanding.

The essential role of $\mathrm{Na} / \mathrm{Pi}-2 \mathrm{a}$ in regulating renal phosphate homeostasis was demonstrated in genetically altered mice in which the $\mathrm{Na} / \mathrm{Pi}-2 \mathrm{a}$ gene was ablated by homologous recombination (Beck et al. 1998). $\mathrm{Na} / \mathrm{Pi}-2 \mathrm{a}^{-/-}$ mice have increased urinary phosphate excretion, resulting in hypophosphatemia. Furthermore, $\mathrm{Na} / \mathrm{Pi}-2 \mathrm{a}^{-/-}$mice also develop hypercalcemia, hypercalciuria, and have low serum level of PTH (Chau et al. 2003). Perhaps as a compensatory effect, the $\mathrm{Na} / \mathrm{Pi}-2 \mathrm{c}$ protein is markedly increased in the brush-border membrane of $\mathrm{Na} / \mathrm{Pi}-2 \mathrm{a}^{-/-}$mice (Tenenhouse et al. 2003). Known regulators of renal phosphate reabsorption, including dietary phosphate intake or PTH administration have no significant effect on renal phosphate transport in $\mathrm{Na} / \mathrm{Pi}-2 \mathrm{a}^{-/-}$mice, suggesting that $\mathrm{Na} / \mathrm{Pi}-2 \mathrm{a}$ is the main regulatory molecule which handles renal phosphate transport activities in the mice (Tenenhouse 2005). It is predicted that in mice, in addition to $\mathrm{Na} / \mathrm{Pi}-2 \mathrm{a}$, about $30 \%$ of renal reabsorption could be mediated through $\mathrm{Na} / \mathrm{Pi}-2 \mathrm{c}$. In humans, however, $\mathrm{Na} / \mathrm{Pi}-2 \mathrm{c}$ cotransporters appear to have a more important role in renal phosphate handling.

Hereditary hypophosphatemic rickets with hypercalciuria (HHRH), an autosomal recessive disorder was first identified in a large Bedouin kindred, and is characterized by hypophosphatemia secondary to renal phosphate wasting, with increased serum levels of $1,25(\mathrm{OH})_{2} \mathrm{D}$ that is associated with intestinal calcium hyperabsorption and hypercalciuria, and rickets and osteomalacia (Tieder et al. 1985). Recently, a genome-wide scan combined with homozygosity mapping has found a single nucleotide deletion in the $\mathrm{Na} / \mathrm{Pi}-2 \mathrm{c}$ cotransporter gene in all affected individuals with HHRH (Bergwitz et al. 2006, Lorenz-Depiereux et al. 2006a). Interestingly, genomic deletion of $\mathrm{Na} / \mathrm{Pi}-2 \mathrm{c}$ from mice has produced minor phenotypes (Segawa et al. 2006) when compared with $\mathrm{Na} / \mathrm{Pi}-2 \mathrm{a}$-ablated mice, again suggesting that there might be differences in the regulation of phosphate homeostasis in humans and mice, and that the $\mathrm{Na} / \mathrm{Pi}-2 \mathrm{c}$ cotransporter may have more important regulatory functions in maintaining phosphate homeostasis in humans. Identification of FGF23, as 'phosphatonin' from tumor-induced osteomalacia (TIO) and patients with autosomal 
dominant hypophosphatemic rickets (ADHR), which could induce urinary phosphate wasting by inhibiting the $\mathrm{Na} / \mathrm{Pi}$ cotransporter system in the kidney has further enhanced our understanding of the renal regulation of phosphate homeostasis.

\section{FGF23}

Human FGF23 was identified by positional cloning as a responsible gene for inducing phosphate wasting in patients with ADHR; gain-of-function mutations in the FGF23 gene were identified in ADHR, that are believed to enhance biological activities of FGF23 to produce distinct clinical symptoms in these patients (ADHR_Consortium 2000). FGF23 was also identified as a causative humoral factor that induces clinical symptoms in patients with TIO; tumors causing TIO have been shown to produce excessive amounts of FGF23 (Shimada et al. 2001). In accordance with human diseases, functional in vivo experimental studies have identified FGF23 as one of the most potent phosphatonins that induce renal phosphate wasting (Bai et al. 2004, Larsson et al. 2004, Shimada et al. 2004a,b, Sitara et al. 2004).

FGF23 could suppress the expression of $\mathrm{Na} / \mathrm{Pi}-2 \mathrm{a}$ and $\mathrm{Na} / \mathrm{Pi}-2 \mathrm{c}$ cotransporters that mediate physiological phosphate uptake in proximal tubular epithelial cells (Shimada et al. 2004c); by suppressing the $\mathrm{Na} / \mathrm{Pi}$ cotransporter system, FGF23 could reduce renal phosphate reabsorption, and thereby increase urinary phosphate wasting. In addition, FGF23, not only suppresses the expression of the $1 \alpha(\mathrm{OH})$ ase, the essential enzyme that mediates the production of the active vitamin $\mathrm{D}$ metabolite, $1,25(\mathrm{OH})_{2} \mathrm{D}$, but could also enhance the expression of 24-hydroxylase, an enzyme that converts $1,25(\mathrm{OH})_{2} \mathrm{D}$ into more hydrophilic metabolites with lesser biological activity (Shimada et al. 2004c). Since $1,25(\mathrm{OH})_{2} \mathrm{D}$ could also enhance intestinal phosphate absorption, FGF23, by reducing vitamin D activities, could reduce serum phosphate levels by inhibiting phosphate absorption in the intestine, in addition to its renal phosphate wasting effects.

FGF23, a $30 \mathrm{kDa}$ protein, is proteolytically processed between arginine179 and serine180 to generate smaller $\mathrm{N}$-terminal $(18 \mathrm{kDa})$ and C-terminal $(12 \mathrm{kDa})$ fragments (Fig. 1). The N-terminal fragment of FGF23 contains the FGF receptor (FGFR)-binding domain; just adjacent to the proteolytic processing site, this amino acid sequence arginine176-X-X-arginine179 is recognized by furin, a subtilisin-like proprotein convertase. Studies have shown that inhibitors for proprotein convertase could also inhibit the processing of the FGF23 protein (Benet-Pages et al. 2004). Although in vivo studies using synthetic peptides have claimed that neither processed N-terminal nor C-terminal fragments of FGF23 have biological activity, in terms of reducing serum phosphate levels (Shimada et al. 2002), the functionality of synthetic peptides might be different than naturally processed fragments. Of relevance, a recent study has shown phosphaturic activities of C-terminal fragments, and peptides corresponding to amino acids 180-205 could induce urinary phosphate wasting (Berndt et al. 2007); despite the absence of the FGFR-binding domain, how the C-terminal could induce urinary phosphate wasting needs to be investigated by carefully designed studies. The C-terminal fragment is also proposed to be necessary for interaction with klotho, which is believed to be a cofactor in FGF23-FGFR interactions (Goetz et al. 2007). Whether a complex generated through FGF23 C-terminal and klotho interaction could activate FGFR to exert phosphaturic effects needs additional study.

A pathological role of FGF23 has also been speculated in patients with McCune-Albright syndrome, a disease usually characterized by skin pigmentation, endocrine disorders, polyostotic fibrous dysplasia of bone, with hypophosphatemia; FGF23 levels have suggested a correlation with disease burden of bone, and hypophosphatemia in these patients (Riminucci et al. 2003). Dysregulation of FGF23 is also involved in a number of other human diseases with abnormal phosphate homeostasis (Table 1). One such disease is X-linked hypophosphatemia (XLH).

FGF23 has been shown to be involved in contributing to $\mathrm{XLH}$, a common cause of vitamin D-resistant rickets/osteomalacia. Positional cloning identified inactivating mutations in PHEX (a phosphate-regulating gene with homologies to endopeptidases on the X-chromosome) in patients with XLH (HYP_Consortium 1995). It is, however, not yet clear how mutations in the PHEX gene induce renal phosphate wasting leading to hypophosphatemia; the high circulatory levels of FGF23 in most of the patients with XLH (Jonsson et al. 2003) suggest that renal phosphate wasting might be the consequence of enhanced activity of FGF23. Hyp mice that carry various inactivating deletions in the Phex gene show comparable phenotypes to patients with XLH (Beck et al. 1997); in accordance with XLH patients, circulatory Fgf23 levels are high in Hyp mice (Liu et al. 2006, Sitara et al. 2006), may be because of increased production of $\mathrm{Fgf} 23$ in the bone (Sitara et al. 2006). The pathological significance of high levels of Fgf 23 in Hyp mice became even more evident from the studies showing that genetic ablation of the Fgf23 gene from Hyp mice reversed the hypophosphatemia to hyperphosphatemia (Sitara et al. 2004). It is, therefore, likely that mutations in the PHEX gene, in a yet unknown mechanism, could enhance the expression of FGF23 in bone that is subsequently released into the circulation to exert its phosphaturic effects in patients with XLH and in Hyp mice.

Recently, mutations in the dentin matrix protein-1 (DMP-1) gene have been shown to be associated with autosomal recessive hypophosphatemic rickets/osteomalacia (ARHR; Feng et al. 2006, Lorenz-Depiereux et al. 2006b). DMP-1, as apparent from the name, is a matrix protein that is mostly produced by osteocytes and odontoblasts. Although the exact mechanism is yet to be determined, the clinical symptoms of hypophosphatemia in patients with ARHR are believed to be due to high circulatory levels of FGF23. Dmp-1 null mice have also high circulatory levels of Fgf23, and showed phenotypes resembling ARHR patients (Feng et al. 2006). 


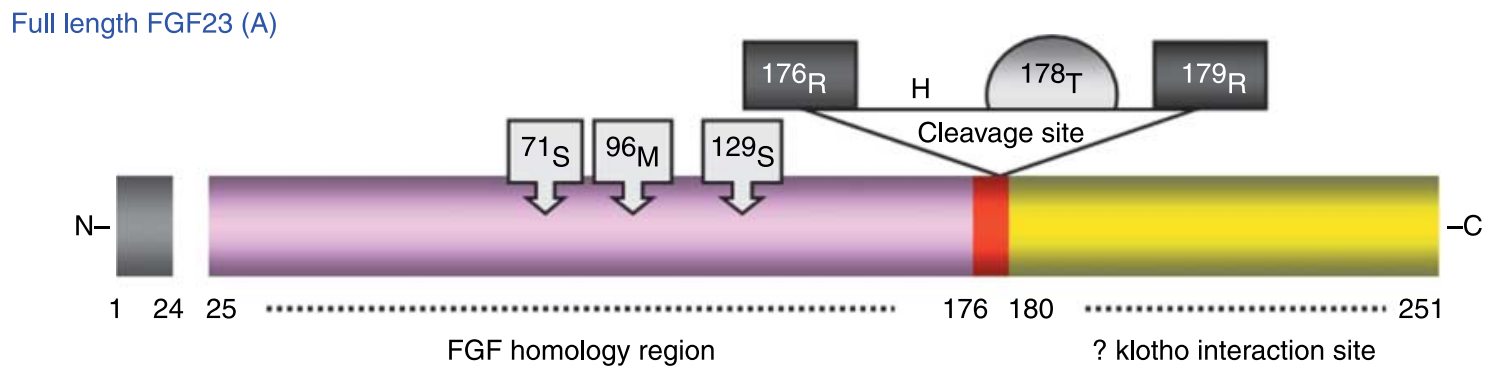

Processed FGF23 (B)

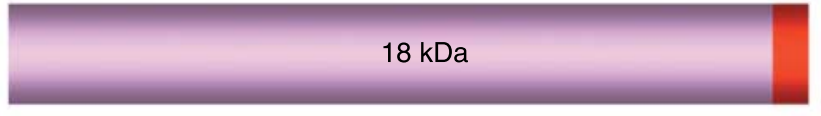

25

(Amino fragment)

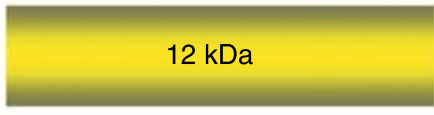

180
(Carboxy fragment)

Klotho (C)

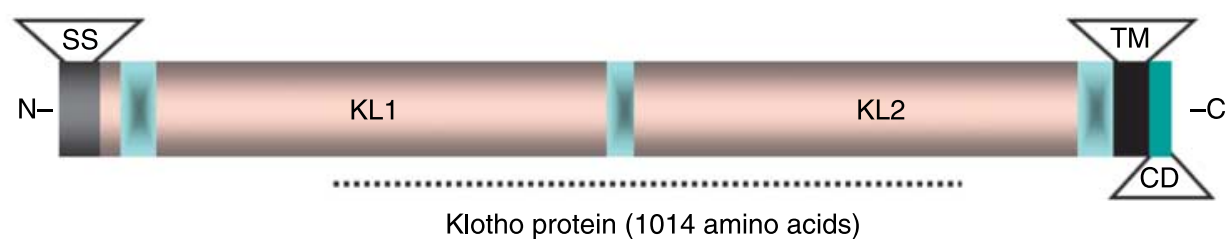

Figure 1 Schematic diagram showing the structure of full-length FGF23 protein (A) with its putative signal peptide (aa 1-24), the amino terminal of FGF23 (aa 25-179) has the homologous region to other known FGFs; the carboxy terminal of FGF23 (aa 180-251) might have possible klotho-interacting site. Moreover, aa 176-179 represents the subtilisin-like cleavage site, where full-length FGF23 protein is cleaved into the smaller $18 \mathrm{kDa}$ amino-terminal and the $12 \mathrm{kDa}$ carboxy-terminal fragments (B). Mutations in ${ }^{176} \mathrm{R}$ and ${ }^{179} \mathrm{R}$ have been reported in patients with $\mathrm{ADHR}$, whereas mutations in ${ }^{71} \mathrm{~S},{ }^{96} \mathrm{M}$, and ${ }^{129} \mathrm{~S}$ have been associated with patients affected by FTC. FGF23 has been shown to be $O$-glycosylated by the enzyme GALNT3 and the major glycosylation site is believed to be ${ }^{178} \mathrm{~T}$, as shown in the diagram. Klotho protein (C) is composed of 1014 amino acids, and possesses a putative signal sequence (SS) at its N-terminus and a putative transmembrane domain (TM) with a short cytoplasmic domain (CD) at the C-terminus. The extracellular domain of the klotho protein consists of two internal repeats (KL1 and KL2) that share sequence homology to the $\beta$-glucosidase.

In contrast to patients with several hypophosphatemic diseases as mentioned earlier, there are contrasting human diseases, including familial tumoral calcinosis (FTC), that are thought to be due to loss of function mutations in the FGF23 gene (Benet-Pages et al. 2005). FTC is characterized by ectopic calcification that is usually associated with hyperphosphatemia. Patients with FTC have enhanced renal tubular phosphate uptake with higher serum levels of $1,25(\mathrm{OH})_{2} \mathrm{D}$, possibly leading to the hyperphosphatemia. Interestingly, $\mathrm{Fg} 23$ null mice also develop hyperphosphatemia with high serum levels of $1,25(\mathrm{OH})_{2} \mathrm{D}$ (Shimada et al. 2004a, Sitara et al. 2004).

In addition to FGF23, recently GALNT3 has been identified by positional cloning as another responsible gene causing FTC (Topaz et al. 2004). This gene encodes a protein called UDP- $N$-acetyl- $\alpha$-D-galactosamine: polypeptide $N$-acetylgalactosaminyltransferase-3 (ppGaNTase-T3) and is involved in post-translational modifications of serine or threonine residues by O-glycation; patients with FTC that
Table 1 Serum parameters in human phosphate wasting diseases. Note that low serum phosphate level is always accompanied by high fibroblast growth factor (FGF)-23 level, irrespective of disease types

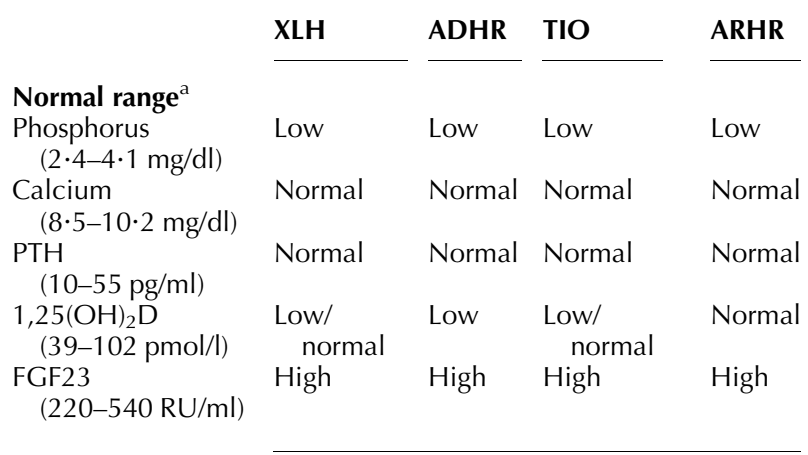

${ }^{\mathrm{a}}$ Normal value ranges may vary among different laboratories. 
is due to mutations in the GALNT3 gene have low circulatory levels of intact FGF23 (Garringer et al. 2006), but exhibit high circulatory levels of the processed C-terminal FGF23 fragment. How mutations in the GALNT3 gene cause enhanced processing of FGF23 needs further study. Recently, ppGaNTase-T3 has been shown to specifically induce O-glycosylation of the threonine178 residue located in the processing site of FGF23 (Kato et al. 2006). This Oglycosylation appears to prevent cleavage of the intact FGF23 protein, by either modifying the protein structure or interfering with the proprotein convertases to access the processing site of FGF23. Of relevance, the FGF23 protein has three $\mathrm{O}$-glycan chains. From the studies of Frishberg et al. (2007), it appears likely that mutations in the GALNT3 gene cause specific impairment of O-glycosylation of threonine178 in the FGF23 protein (Frishberg et al. 2007), and defects in glycosylation may facilitate rapid processing of the protein, while the fully glycosylated FGF23 protein is resistant to processing. Such a phenomenon might explain why patients with FTC due to GALNT3 mutation have low circulatory intact FGF23 but high processed C-terminal FGF23 (Garringer et al. 2006).

Circulatory FGF23 levels are also extremely high in patients with CKD (Larsson et al. 2003, Imanishi et al. 2004). The exact role of elevated circulatory levels of FGF23 in CKD patients is not clear, and whether low levels of vitamin D, and secondary hyperparathyroidism that are noted in CKD patients are influenced by increased circulatory levels of FGF23 is a complex issue; since FGF23 is a counter regulatory hormone for vitamin $\mathrm{D}$, it is likely that elevated circulatory levels of FGF23 might contribute to the hypovitaminosis D in CKD patients, and that might eventually facilitate the development of compensatory secondary hyperparathyroidism. Of relevance, the administration of FGF23 reduces the expression of the $1 \alpha(\mathrm{OH})$ ase mRNA and protein in experimental animals, while genetic ablation of the $F g f 23$ gene from mice is associated with upregulation of the renal $1 \alpha(\mathrm{OH})$ ase that is associated with an increase in serum levels of $1 \alpha, 25(\mathrm{OH})_{2} \mathrm{D}$ (Shimada et al. 2001, Razzaque et al. 2006). The etiological diversity, along with multi-stage, multifactorial molecular events of different stages of CKD (Eddy \& Neilson 2006, Taguchi \& Razzaque 2007) make it clinically difficult to pinpoint and target one single risk factor to minimize or delay the progression of the disease; the conventional treatment of CKD patients, either with vitamin $\mathrm{D}$ analogs or PTH-lowering drugs, could theoretically be more effective, if FGF23 levels are also therapeutically reduced to eliminate its counter regulatory effects on vitamin D.

\section{In vivo functional studies on genetically altered Fgf23 mouse models}

The understanding of the in vivo effects of FGF23 on the regulation of phosphate homeostasis has been significantly enhanced by the generation of Fgf23 knockout and transgenic models. In 2004, two separate groups have reported the effects of genetic ablation of Fgf23 on phosphate homeostasis (Shimada et al. 2004a, Sitara et al. 2004). Both studies have found that Fgf23 null mice develop severe hyperphosphatemia starting in early life, due to increased renal phosphate uptake by the $\mathrm{Na} / \mathrm{Pi}-2 \mathrm{a}$ cotransporter; such abnormal phosphate homeostasis in the mutant mice affects skeletal mineralization and produces extensive soft tissue calcifications (Fig. 2; Razzaque et al. 2005, Lanske \& Razzaque 2007a), and the resultant effect being shortened lifespan. To determine the exact physiological role of the increased renal expression of sodium-phosphate cotransporter (NaPi-2a) protein in Fgf23 null mice, we have ablated of $\mathrm{NaPi}-2 \mathrm{a}$ gene from $\mathrm{Fg} f 23^{-/-}$ mice, and found that hypersphosphatemia of $\mathrm{Fgf2} 23^{-1-}$ mice reversed to hypophosphatemia in $\mathrm{NaPi}-2 a^{-/-} / \mathrm{Fgf2} 3^{-/-}$ mice by 6 weeks of age, providing the genetic evidence of the importance of $\mathrm{NaPi}-2 \mathrm{a}$ in regulating renal phosphate homeostasis in Fgf23 $3^{-/-}$mice (Sitara et al. 2006).

More importantly, the phenotype of Fgf23 null animals resembles the one of the patients with FTC, an autosomal recessive disorder characterized by ectopic calcifications and elevated serum levels of phosphate due to inactivating mutations in the FGF23 gene (Benet-Pages et al. 2005). Conversely, the phenotype of FGF23 transgenic animals mimics the one of the patients with ADHR carrying mutations in the FGF23 gene located within three nucleotides between residues 176 and 179 in the proprotein convertase cleavage site (ADHR_Consortium 2000); these mutations change arginine residues at 176 and/or 179 to

Table 2 Serum parameters in fibroblast growth factor-23 (Fgf23) knockout (Fgf23 ${ }^{-/}$) and FGF23 transgenic (FGF23Tg) mice. Note the opposing effects in all measured serum parameters in Fgf23 $3^{-}$(Shimada et al. 2004a, Sitara et al. 2004) and FGF23Tg mice (Bai et al. 2004, Larsson et al. 2004, Shimada et al. 2004b). The high and low serum values are determined in comparison with the values of control mice that are shown as normal

\begin{tabular}{|c|c|c|c|}
\hline & Control & Fgf $23^{-1-}$ & FGF23 Tg \\
\hline Phosphorus & Normal (8-10 mg/dl) & $\operatorname{High}(>16 \mathrm{mg} / \mathrm{dl})$ & $\operatorname{Low}(<6 \mathrm{ml} / \mathrm{dl})$ \\
\hline Calcium & Normal (8-10 mg/dl) & High $(>11 \mathrm{mg} / \mathrm{dl})$ & $\operatorname{Low}(\sim 8 \mathrm{mg} / \mathrm{dl})$ \\
\hline PTH & Normal $(20-80 \mathrm{pg} / \mathrm{ml})$ & Low (not detectable) & $\operatorname{High}(>200 \mathrm{pg} / \mathrm{ml})^{\mathrm{a}}$ \\
\hline $1,25(\mathrm{OH})_{2} \mathrm{D}$ & Normal $(\sim 150 \mathrm{pg} / \mathrm{ml})^{\mathrm{b}}$ & High $(>400 \mathrm{pg} / \mathrm{ml})$ & Low $(<100 \mathrm{pg} / \mathrm{ml})$ \\
\hline FGF23 & Normal ( 100 RU/ml) & Absent (0 RU/ml) & High $(>7500 \mathrm{RU} / \mathrm{ml})$ \\
\hline
\end{tabular}

${ }^{\text {a }}$ Shimada et al. in their transgenic mice reported no elevation of serum PTH level.

b Levels of $1,25(\mathrm{OH})_{2}$ D can vary as much as $30 \%$, depending on the method of measurements. 

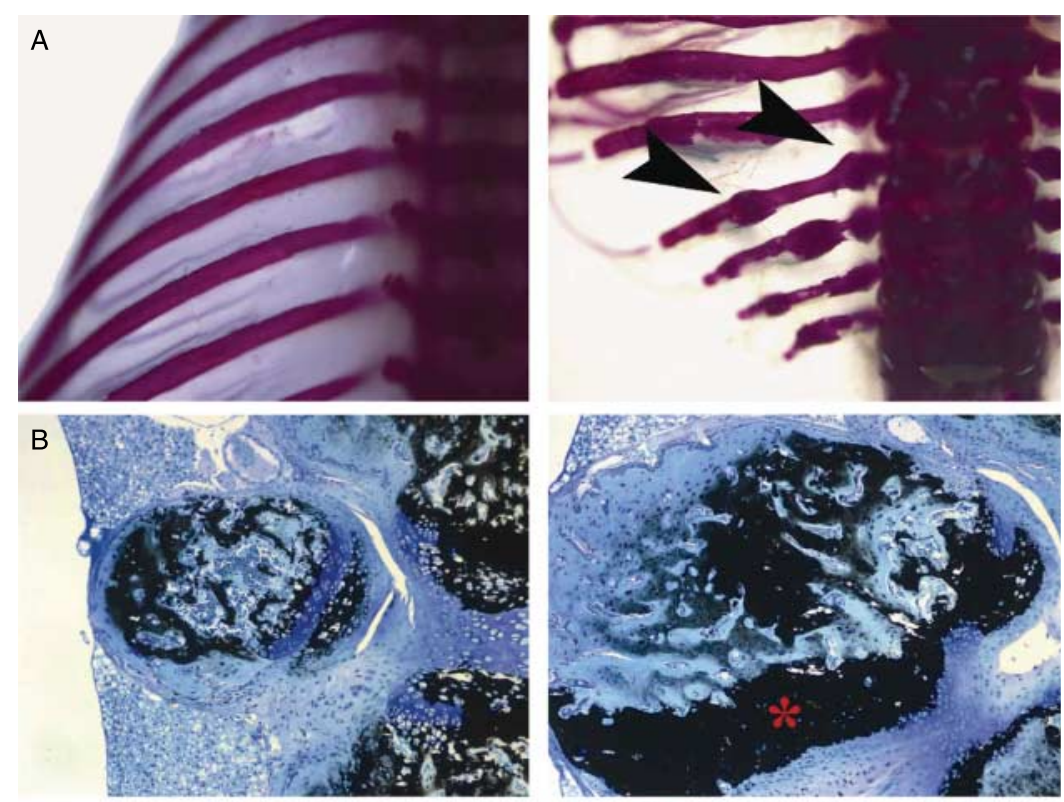

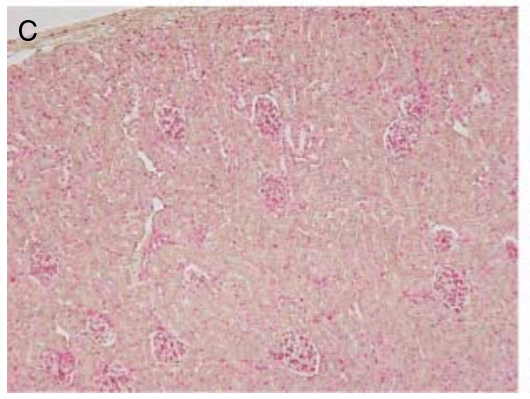

WT

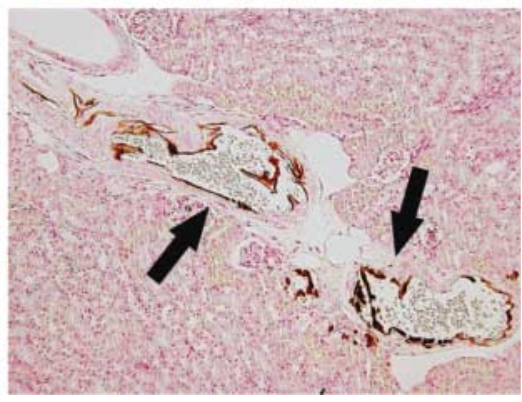

$\mathrm{Fgf23}^{-/-}$

Figure 2 Altered mineralization in bone and kidney of Fgf23 knockout (Fgf23 ${ }^{-/}$) mice. Note abnormal nodular lesions (arrow) in the ribs of Fgf $23^{-1-}$ mice, compared with control (A). Histomorphometric analysis on methyl methacrylate sections, stained with toluidine blue and von Kossa's stains, shows increased mineral deposition (black) in the mutant ribs (asterisk; B). It is worth to mention that in Fgf23 $3^{-1-}$ mice, skeletal mineralization has heterogeneous distribution, where increased mineral deposition is also accompanied with unmineralized osteoid (light blue) formation (B). Extensive soft tissue mineralization is a characteristic feature in Fgf $23^{-1-}$ mice, as shown here in the kidney (C).

glutamine or other residues to prevent proteolytic cleavage of the FGF23 protein by furin to presumably inactive fragments; the net effect being phosphate wasting in the affected patients, perhaps due to enhanced biologic activities of FGF23 (White et al. 2001).

In 2004, three separate groups also reported the generation of transgenic mice over-expressing Fgf23/FGF23 (Bai et al. 2004, Larsson et al. 2004, Shimada et al. 2004b); these mice have hypophosphatemia, due to suppression of the renal $\mathrm{Na} / \mathrm{Pi}$ cotransporters; the long-term effect of hypophosphatemia in these mutant mice is evident from obvious skeletal mineral defects in the form of rickets/osteomalacia. Of relevance, the biochemical changes of Fgf23/FGF23 transgenic mice are essentially opposite from those noted in Fgf23 null mice (Table 2); these genetically modified animal models have not only provided insights into the role of FGF23 in regulating phosphate homeostasis, but also provided the in vivo tool to study in depth the biology of FGF23. Existing information supports the notion that FGF23 is the master molecule which regulates renal phosphate metabolism (Berndt \& Kumar 2007, Fukumoto \& Yamashita 2007, Lanske \& Razzaque 2007b). However, how FGF23 exerts its bioactivities is an intense area of research, and preliminary observations suggest that it interacts with FGFRs in the presence of klotho to exert its functions (Fig. 3; Yu et al. 2005, Goetz et al. 2007).

\section{Klotho}

The Klotho protein contains 1014 amino acids with a putative signal sequence at its $\mathrm{N}$-terminus and a single transmembrane domain near its C-terminus which is believed to anchor the protein to the membrane. Since the klotho gene encodes a type 1 membrane protein, it was predicted to be present on the cell surface of klotho-expressing cells. However, the 
extracellular domain of klotho could be cleaved and detectable in the blood and cerebrospinal fluid. The klotho, therefore, could act as a circulating hormone. The extracellular domain of the klotho protein has two internal repeats, termed KL-1 and KL-2 (Fig. 1). KL-1 and KL-2 have sequence homology to $\beta$-glucosidase of bacteria and plants. Human Klotho has about $86 \%$ homology to mouse klotho and is mapped to chromosome 13q12 (Matsumura et al. 1998). Klotho expression is observed in restrictive tissues and is predominantly present in tissues that regulate calcium homeostasis, including the distal convoluted tubules in the kidney, parathyroid gland, and the epithelium of the choroid plexus in the brain (Matsumura et al. 1998). Inactivation of klotho activities could produce extensive premature aginglike features in the mouse (Kuro-o et al. 1997). Interestingly, demonstration of similar premature aging-like features in Fgf23-ablated mice, as klotho-ablated mice, has facilitated the identification of a common signaling cascade through which FGF23 exerts its bioactivities (Razzaque et al. 2006, Razzaque \& Lanske 2006, Lanske \& Razzaque 2007c).

\section{How FGF23 exerts its bioactivities?}

Most of the FGF family members exert their functions through interacting with FGFRs. To date, four FGFRs with alternative spliced variants for each of them have been reported (Goldfarb 2005, Mohammadi et al. 2005). For instance, alternative splicing of an exon coding for the third immunoglobulin-like loop produces three different subtypes of FGFR1, namely FGFR1a, FGFR1b, and FGFR1c. Similarly, alternative splicing produces two subtypes of FGFR2 and FGFR3, namely FGFR2b, FGFR2c, FGFR3b, and FGFR3c. Several studies, using the Biacore system, have suggested that FGF23 has the ability to interact with FGFR1c, FGFR2c, FGFR3c, and FGFR4 (Yamashita et al. 2002, Yu et al. 2005). Despite the ubiquitous presence of FGFRs, the induction of FGF23-responsive downstream molecules, such as activation of early growth response (Egr)-1 and phosphorylation of ERK protein were only detected in very restricted tissues that include kidney, parathyroid, and pituitary glands, when mice and rats were treated with recombinant FGF23 protein (Urakawa et al. 2006); such observations suggest that FGF23 might have selective effects on specific tissues that might be different from most of the other members of the FGF family. Considering the unique biological activities of FGF23, which is mostly produced in the bone (Sitara et al. 2006), but exerts most of its functions in the kidney, existence of a novel humoral signaling pathway is likely. A major breakthrough of how FGF23 exerts its bioactivities has been achieved by the recent demonstration of strikingly similar physical and biochemical phenotypes of Fgf23 knockout with klotho hypomorph mice (Kuro-o et al. 1997, Razzaque et al. 2006, Razzaque \& Lanske 2006). Such extremely high similarities in phenotypes (Table 3) suggest a functional relationship between these molecules, and this has

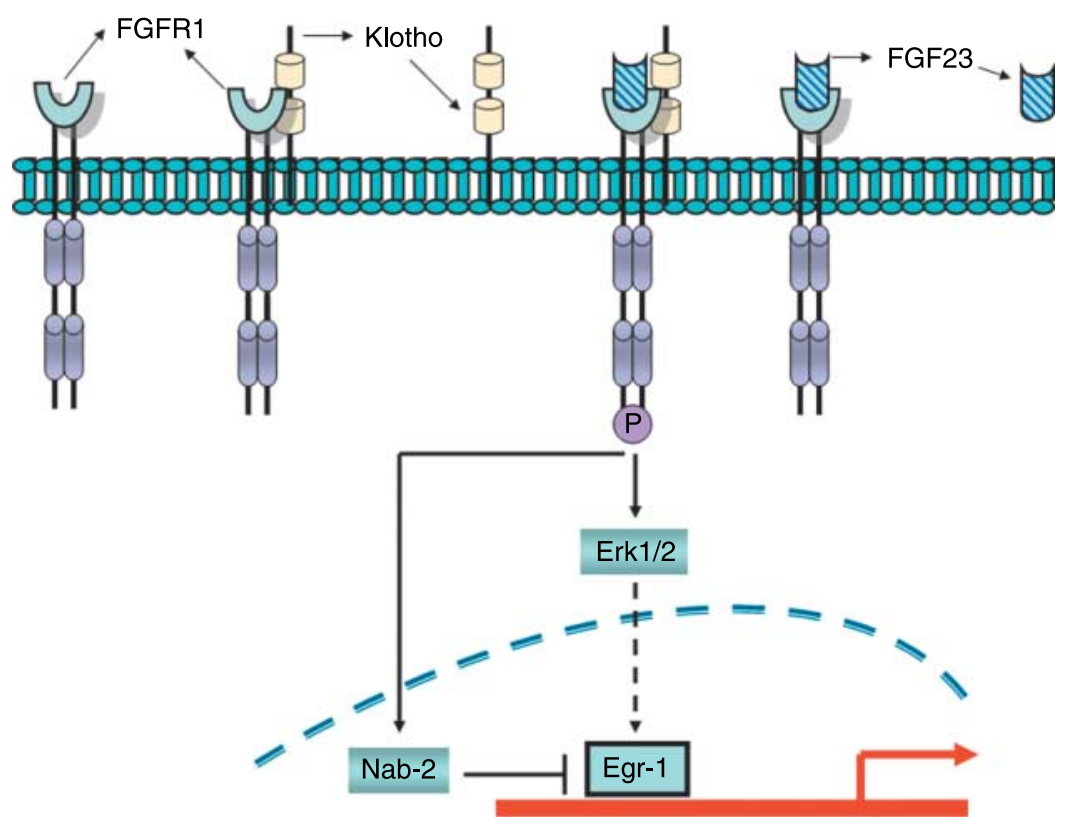

Figure 3 Schematic outline of FGF23-FGFR interactions. Signaling of FGF23-FGFR involves klotho as a cofactor to induce such downstream signaling molecules as Erk1/2, which could influence the activation of Egr-1. FGF23 also induces Nab-2 (Fukuda et al. 2007), specific corepressor of Egr-1 that could suppress the transcriptional activity of Egr1 , and thereby establish a negative feedback loop to regulate physiological activities of FGF23. 
Table 3 Similarities between fibroblast growth factor 23 (Fgf23)and klotho-ablated mice. Comparison of phenotype between Fgf $23^{-1-}$ and klotho-ablated mice (Kuro-o et al. 1997, Razzaque et al. 2006). Note remarkable physical, biochemical, and morphological similarities in the phenotypes of Fgf23 and klotho mutants (Razzaque \& Lanske 2006)
Fgf23 mutant

Phenotypes

Gross appearances Body weight

Growth retardation

Kyphosis

Physical activity

Gait walk

Body hair

Generalized atrophy

Thymus atrophy

Spleen atrophy

Muscle wasting

Skin atrophy

Intestinal atrophy

Morphological changes

Atherosclerosis/art- Present eriosclerosis

Ectopic calcifica-

tions

Altered skeletal

mineralization

Osteopenia/rickets

Emphysema

Renal NaPi-2a

expression

Serum

$1,25(\mathrm{OH})_{2} \mathrm{D}_{3}$

Serum phosphate

Serum calcium

Serum PTH

Serum FGF23

Overall affect

Infertility

Lifespan
Hypogonadism

Biochemical changes
Reduced

Present

Present

Sluggish

Present

Sparse

Present

Present

Present

Present

Present

Present

Present

Present

Present

Present

Increased

High

High

High

Low

Absent

Present

Short
Klotho mutant

Reduced

Present

Present

Sluggish

Present

Sparse

Present

Present

Present

Present

Not known

Present

Present

Present

Present

Present

Present

Increased

High

High

High

Low

High

Present

Short led to the identification of klotho as a cofactor in FGF23 and its receptor interactions, and subsequent signaling (Fig. 3).

The klotho extracellular domain is believed to facilitate FGF23 binding to its receptor complex with much higher affinity than to FGFR alone, implicating klotho as a cofactor in FGF23-FGFR interaction and subsequent signaling (Kuro-o 2006). In vitro studies have shown that FGF23-non-responsive cells get responsive to FGF23 in the presence of klotho. Such responsiveness was determined by enhanced phosphorylation of ERK and induction of Egr-1 (Urakawa et al. 2006), implying that klotho is required for eliciting downstream FGF23 signaling, and thereby its functions. Using L6 cells that lack FGFRs, it has been shown that FGF23 could not induce downstream signaling events, even after transfection of a klotho-expressing vector (Urakawa et al. 2006), clearly suggesting that FGF23 exerts its functions through interacting with FGFRs, in the presence of klotho. Further studies are needed to determine how and where klotho binds during FGF23 receptor interactions. Klotho has been suggested to bind to FGFRs, including FGFR1c, FGFR 3c, and FGFR4, and that FGF23 could only bind to klotho-FGFR1c, klotho-FGFR3c, and klothoFGFR 4 complexes (Kuro-o 2006). On the other hand, Urakawa et al. (2006) in their recent study have shown that klotho could even bind to FGF23, and artificial induction of klotho protein could create a specific binding site for FGF23 in cultured cells (Urakawa et al. 2006). Further studies are needed to clarify the exact nature of the FGF23-klotho interaction; existing information, however, suggests that klotho converts canonical FGFR into a specific receptor for FGF23.

Now that we know the importance of the FGF23-klotho axis, in retrospect, it is, therefore, not very surprising to find extreme similarities in the phenotype of both Fgf 23 and klotho-ablated mice that include but are not limited to shortened lifespan, impaired sexual maturation leading to infertility, kyphosis, atherosclerosis, extensive soft tissue calcifications, skin atrophy, muscle wasting, T-cell dysregulation, pulmonary emphysema, osteopenia, abnormal mineral ion metabolism, and impaired vitamin $\mathrm{D}$ homeostasis (Razzaque \& Lanske 2006).

\section{Concluding remarks}

In this brief article, based on experimental observations, we have presented our views on how the newly discovered FGF23klotho axis could regulate phosphate homeostasis by affecting the renal $\mathrm{Na} / \mathrm{Pi}$ system, and how altered regulation of one of these molecules could adversely affect mineral ion metabolism to induce disease pathology in both soft tissues and bone. The renal $\mathrm{Na} / \mathrm{Pi}$ cotransporters expressed in the brush-border membrane of proximal tubular epithelial cells are responsible for reabsorbtion of the bulk of the filtered phosphate. FGF23, by suppressing the $\mathrm{Na} / \mathrm{Pi}$ cotransporter system in the kidney, could induce urinary phosphate wasting. Finally, in this article, we wanted to emphasize the importance of the FGF23-klotho axis in regulating mineral ion metabolism. At this stage, FGF23 that is produced in bone appears to exert its hormonal effects in the kidney, and perhaps in the parathyroid gland, in the presence of klotho to regulate mineral metabolism. In less than a decade after identification of FGF23, studying the human hypo- and hyperphosphatemic disorders that are associated with FGF23 dysregulation has significantly improved our overall understanding of hormonal regulation of mineral ion metabolism. A comprehensive understanding of the FGF23-klotho axis on the physiologic adaptation following dietary phosphate uptake, and their coordinated effects on PTH and $1,25(\mathrm{OH})_{2} \mathrm{D}$ will help us to explain how altered regulation of factors controlling mineral ion homeostasis could adversely affect disease pathology. 


\section{Acknowledgements}

Research support from Harvard School of Dental Medicine, Boston, MA and technical assistance from Drs Despina Sitara (Boston, USA), Reinhold G Erben (Vienna, Austria), and Takashi Taguchi (Nagasaki, Japan) are kindly acknowledged. The authors declare that there is no conflict of interest that would prejudice the impartiality of this scientific work.

\section{References}

ADHR_Consortium 2000 Autosomal dominant hypophosphataemic rickets is associated with mutations in FGF23. The ADHR consortium. Nature Genetics 26 345-348.

Bai X, Miao D, Li J, Goltzman D \& Karaplis AC 2004 Transgenic mice overexpressing human fibroblast growth factor 23(R176Q) delineate a putative role for parathyroid hormone in renal phosphate wasting disorders. Endocrinology 145 5269-5279.

Beck L, Soumounou Y, Martel J, Krishnamurthy G, Gauthier C, Goodyer CG \& Tenenhouse HS 1997 Pex/PEX tissue distribution and evidence for a deletion in the $3^{\prime}$ region of the Pex gene in X-linked hypophosphatemic mice. Journal of Clinical Investigation 99 1200-1209.

Beck L, Karaplis AC, Amizuka N, Hewson AS, Ozawa H \& Tenenhouse HS 1998 Targeted inactivation of Npt2 in mice leads to severe renal phosphate wasting, hypercalciuria, and skeletal abnormalities. PNAS 95 5372-5377.

Benet-Pages A, Lorenz-Depiereux B, Zischka H, White KE, Econs MJ \& Strom TM 2004 FGF23 is processed by proprotein convertases but not by PHEX. Bone 35 455-462.

Benet-Pages A, Orlik P, Strom TM \& Lorenz-Depiereux B 2005 An FGF23 missense mutation causes familial tumoral calcinosis with hyperphosphatemia. Human Molecular Genetics 14 385-390.

Bergwitz C, Roslin NM, Tieder M, Loredo-Osti JC, Bastepe M, Abu-Zahra H, Frappier D, Burkett K, Carpenter TO, Anderson D et al. 2006 SLC34A3 mutations in patients with hereditary hypophosphatemic rickets with hypercalciuria predict a key role for the sodium-phosphate cotransporter $\mathrm{NaPi}-\mathrm{IIc}$ in maintaining phosphate homeostasis. American Journal of Human Genetics 78 179-192.

Berndt T \& Kumar R 2007 Phosphatonins and the regulation of phosphate homeostasis. Annual Review of Physiology 69 341-359.

Berndt TJ, Craig TA, McCormick DJ, Lanske B, Sitara D, Razzaque MS, Pragnell M, Bowe AE, O'Brien SP, Schiavi SC et al. 2007 Biological activity of FGF-23 fragments. Pflugers Archiv 454 615-623.

Biber J, Custer M, Werner A, Kaissling B \& Murer H 1993 Localization of $\mathrm{NaPi}-1$, a $\mathrm{Na} / \mathrm{Pi}$ cotransporter, in rabbit kidney proximal tubules. II. Localization by immunohistochemistry. Pflugers Archiv 424 210-215.

Chau H, El-Maadawy S, McKee MD \& Tenenhouse HS 2003 Renal calcification in mice homozygous for the disrupted type IIa $\mathrm{Na} / \mathrm{Pi}$ cotransporter gene Npt2. Journal of Bone and Mineral Research 18 644-657.

Custer M, Lotscher M, Biber J, Murer H \& Kaissling B 1994 Expression of $\mathrm{Na}-\mathrm{P}(\mathrm{i})$ cotransport in rat kidney: localization by RT-PCR and immunohistochemistry. American Journal of Physiology 266 F767-F774.

Eddy AA \& Neilson EG 2006 Chronic kidney disease progression. Journal of the American Society of Nephrology 17 2964-2966.

Feng JQ, Ward LM, Liu S, Lu Y, Xie Y, Yuan B, Yu X, Rauch F, Davis SI, Zhang S et al. 2006 Loss of DMP1 causes rickets and osteomalacia and identifies a role for osteocytes in mineral metabolism. Nature Genetics $\mathbf{3 8}$ $1310-1315$.

Forster IC, Hernando N, Biber J \& Murer H 2006 Proximal tubular handling of phosphate: A molecular perspective. Kidney International 70 1548-1559.

Frishberg Y, Ito N, Rinat C, Yamazaki Y, Feinstein S, Urakawa I, NavonElkan P, Becker-Cohen R, Yamashita T, Araya K et al. 2007 Hyperostosishyperphosphatemia syndrome: a congenital disorder of $\mathrm{O}$-glycosylation associated with augmented processing of fibroblast growth factor 23 . Journal of Bone and Mineral Research 22 235-242.
Fukuda T, Kanomata K, Nojima J, Urakawa I, Suzawa T, Imada M, Kukita A, Kamijo R, Yamashita T \& Katagiri T 2007 FGF23 induces expression of two isoforms of NAB2, which are corepressors of Egr-1. Biochemical and Biophysical Research Communications 353 147-151.

Fukumoto S \& Yamashita T 2007 FGF23 is a hormone-regulating phosphate metabolism-unique biological characteristics of FGF23. Bone 40 1190-1195.

Gaasbeek A \& Meinders AE 2005 Hypophosphatemia: an update on its etiology and treatment. American Journal of Medicine 118 1094-1101.

Garringer HJ, Fisher C, Larsson TE, Davis SI, Koller DL, Cullen MJ, Draman MS, Conlon N, Jain A, Fedarko NS et al. 2006 The role of mutant UDP-Nacetyl-alpha-D-galactosamine-polypeptide $\mathrm{N}$-acetylgalactosaminyltransferase 3 in regulating serum intact fibroblast growth factor 23 and matrix extracellular phosphoglycoprotein in heritable tumoral calcinosis. Journal of Clinical Endocrinology and Metabolism 91 4037-4042.

Goetz R, Beenken A, Ibrahimi OA, Kalinina J, Olsen SK, Eliseenkova AV, Xu C, Neubert T, Zhang F, Linhardt RJ et al. 2007 Molecular Insights into the Klotho-Dependent, Endocrine Mode of Action of FGF19 Subfamily Members. Molecular and Cellular Biology 27 3417-3428.

Goldfarb M 2005 Fibroblast growth factor homologous factors: evolution, structure, and function. Cytokine and Growth Factor Reviews 16 215-220.

Hilfiker H, Hattenhauer O, Traebert M, Forster I, Murer H \& Biber J 1998 Characterization of a murine type II sodium-phosphate cotransporter expressed in mammalian small intestine. PNAS 95 14564-14569.

HYP_Consortium 1995 A gene (PEX) with homologies to endopeptidases is mutated in patients with X-linked hypophosphatemic rickets. Nature Genetics 11 130-136.

Imanishi Y, Inaba M, Nakatsuka K, Nagasue K, Okuno S, Yoshihara A, Miura M, Miyauchi A, Kobayashi K, Miki Tet al. 2004 FGF-23 in patients with end-stage renal disease on hemodialysis. Kidney International 65 1943-1946.

Jonsson KB, Zahradnik R, Larsson T, White KE, Sugimoto T, Imanishi Y, Yamamoto T, Hampson G, Koshiyama H, Ljunggren O et al. 2003 Fibroblast growth factor 23 in oncogenic osteomalacia and X-linked hypophosphatemia. New England Journal of Medicine 348 1656-1663.

Kato K, Jeanneau C, Tarp MA, Benet-Pages A, Lorenz-Depiereux B, Bennett EP, Mandel U, Strom TM \& Clausen H 2006 Polypeptide GalNActransferase T3 and familial tumoral calcinosis. Secretion of fibroblast growth factor 23 requires O-glycosylation. Journal of Biological Chemistry 281 18370-18377.

Kavanaugh MP, Miller DG, Zhang W, Law W, Kozak SL, Kabat D \& Miller AD 1994 Cell-surface receptors for gibbon ape leukemia virus and amphotropic murine retrovirus are inducible sodium-dependent phosphate symporters. PNAS 91 7071-7075.

Kuro-o M 2006 Klotho as a regulator of fibroblast growth factor signaling and phosphate/calcium metabolism. Current Opinion in Nephrology and Hypertension 15 437-441.

Kuro-o M, Matsumura Y, Aizawa H, Kawaguchi H, Suga T, Utsugi T, Ohyama Y, Kurabayashi M, Kaname T, Kume E et al. 1997 Mutation of the mouse klotho gene leads to a syndrome resembling ageing. Nature 390 $45-51$.

Lanske B \& Razzaque MS 2007a Premature aging in klotho mutant mice: cause or consequence? Ageing Research Reviews 6 73-79.

Lanske B \& Razzaque MS $2007 b$ Vitamin-D and aging: old concepts and new insights. Journal of Nutritional Biochemistry In press.

Lanske B \& Razzaque MS 2007c Mineral metabolism and aging: the FGF-23 enigma. Current Opinion in Nephrology and Hypertension 16 311-318.

Larsson T, Nisbeth U, Ljunggren O, Juppner H \& Jonsson KB 2003 Circulating concentration of FGF-23 increases as renal function declines in patients with chronic kidney disease, but does not change in response to variation in phosphate intake in healthy volunteers. Kidney International 64 2272-2279.

Larsson T, Marsell R, Schipani E, Ohlsson C, Ljunggren O, Tenenhouse HS, Juppner H \& Jonsson KB 2004 Transgenic mice expressing fibroblast growth factor 23 under the control of the alpha1(I) collagen promoter exhibit growth retardation, osteomalacia, and disturbed phosphate homeostasis. Endocrinology 145 3087-3094.

Liu S, Zhou J, Tang W, Jiang X, Rowe DW \& Quarles LD 2006 Pathogenic role of Fgf23 in Hyp mice. American Journal of Physiology. Endocrinology and Metabolism 291 E38-E49. 
Lorenz-Depiereux B, Benet-Pages A, Eckstein G, Tenenbaum-Rakover Y, Wagenstaller J, Tiosano D, Gershoni-Baruch R, Albers N, Lichtner P, Schnabel D et al. 2006a Hereditary hypophosphatemic rickets with hypercalciuria is caused by mutations in the sodium-phosphate cotransporter gene SLC34A3. American Journal of Human Genetics 78 193-201.

Lorenz-Depiereux B, Bastepe M, Benet-Pages A, Amyere M, Wagenstaller J, Muller-Barth U, Badenhoop K, Kaiser SM, Rittmaster RS, Shlossberg AH et al. 2006b DMP1 mutations in autosomal recessive hypophosphatemia implicate a bone matrix protein in the regulation of phosphate homeostasis. Nature Genetics 38 1248-1250.

Matsumura Y, Aizawa H, Shiraki-Iida T, Nagai R, Kuro-o M \& Nabeshima Y 1998 Identification of the human klotho gene and its two transcripts encoding membrane and secreted klotho protein. Biochemical and Biophysical Research Communications 242 626-630.

Mohammadi M, Olsen SK \& Ibrahimi OA 2005 Structural basis for fibroblast growth factor receptor activation. Cytokine and Growth Factor Reviews 16 107-137.

Razzaque MS \& Lanske B 2006 Hypervitaminosis D and premature aging: lessons learned from Fgf23 and Klotho mutant mice. Trends in Molecular Medicine 12 298-305.

Razzaque MS, St-Arnaud R, Taguchi T \& Lanske B 2005 FGF-23, vitamin D and calcification: the unholy triad. Nephrology, Dialysis, Transplantation 20 2032-2035.

Razzaque MS, Sitara D, Taguchi T, St-Arnaud R \& Lanske B 2006 Premature ageing-like phenotype in fibroblast growth factor 23 null mice is a vitaminD mediated process. FASEB Journal 20 720-722.

Riminucci M, Collins MT, Fedarko NS, Cherman N, Corsi A, White KE, Waguespack S, Gupta A, Hannon T, Econs MJ et al. 2003 FGF-23 in fibrous dysplasia of bone and its relationship to renal phosphate wasting. Journal of Clinical Investigation 112 683-692.

Segawa H, Kaneko I, Takahashi A, Kuwahata M, Ito M, Ohkido I, Tatsumi S \& Miyamoto K 2002 Growth-related renal type II Na/Pi cotransporter. Journal of Biological Chemistry 277 19665-19672.

Segawa H, Onitsuka A, Shiozawa K, Aranami F, Tatsumi S, Ito M, Kuwahata M \& Miyamoto K 2006 Roles of Type IIc Na/Pi Cotransporters in Body Pi Homeostasis. Journal of the American Society of Nephrology 17 355A.

Shimada T, Mizutani S, Muto T, Yoneya T, Hino R, Takeda S, Takeuchi Y, Fujita T, Fukumoto S \& Yamashita T 2001 Cloning and characterization of FGF23 as a causative factor of tumor-induced osteomalacia. PNAS 98 6500-6505.

Shimada T, Muto T, Urakawa I, Yoneya T, Yamazaki Y, Okawa K, Takeuchi Y, Fujita T, Fukumoto S \& Yamashita T 2002 Mutant FGF-23 responsible for autosomal dominant hypophosphatemic rickets is resistant to proteolytic cleavage and causes hypophosphatemia in vivo. Endocrinology 143 31793182 .

Shimada T, Kakitani M, Yamazaki Y, Hasegawa H, Takeuchi Y, Fujita T, Fukumoto S, Tomizuka K \& Yamashita T 2004a Targeted ablation of FGF23 demonstrates an essential physiological role of FGF23 in phosphate and vitamin D metabolism. Journal of Clinical Investigation 113 561-568.

Shimada T, Urakawa I, Yamazaki Y, Hasegawa H, Hino R, Yoneya T, Takeuchi Y, Fujita T, Fukumoto S \& Yamashita T 2004b FGF-23 transgenic mice demonstrate hypophosphatemic rickets with reduced expression of sodium phosphate cotransporter type IIa. Biochemical and Biophysical Research Communications 314 409-414.
Shimada T, Hasegawa H, Yamazaki Y, Muto T, Hino R, Takeuchi Y, Fujita T, Nakahara K, Fukumoto S \& Yamashita T 2004c FGF-23 is a potent regulator of vitamin D metabolism and phosphate homeostasis. Journal of Bone and Mineral Research 19 429-435.

Sitara D, Razzaque MS, Hesse M, Yoganathan S, Taguchi T, Erben RG, Jueppner H \& Lanske B 2004 Homozygous ablation of fibroblast growth factor-23 results in hyperphosphatemia and impaired skeletogenesis, and reverses hypophosphatemia in Phex-deficient mice. Matrix Biology 23 421-432.

Sitara D, Razzaque MS, St-Arnaud R, Huang W, Taguchi T, Erben RG \& Lanske B 2006 Genetic ablation of vitamin D activation pathway reverses biochemical and skeletal anomalies in Fgf-23-null animals. American Journal of Pathology $1692161-2170$.

Soumounou Y, Gauthier C \& Tenenhouse HS 2001 Murine and human type I Na-phosphate cotransporter genes: structure and promoter activity. American Journal of Physiology. Renal Physiology 281 F1082-F1091.

Taguchi T \& Razzaque MS 2007 The collagen-specific molecular chaperone HSP 47: is there a role in fibrosis? Trends in Molecular Medicine 13 45-53.

Tenenhouse HS 2005 Regulation of phosphorus homeostasis by the type iia na/phosphate cotransporter. Annual Review of Nutrition 25 197-214.

Tenenhouse HS, Martel J, Gauthier C, Segawa H \& Miyamoto K 2003 Differential effects of Npt2a gene ablation and X-linked Hyp mutation on renal expression of Npt2c. American Journal of Physiology. Renal Physiology 285 F1271-F1278

Tieder M, Modai D, Samuel R, Arie R, Halabe A, Bab I, Gabizon D \& Liberman UA 1985 Hereditary hypophosphatemic rickets with hypercalciuria. New England Journal of Medicine 312 611-617.

Topaz O, Shurman DL, Bergman R, Indelman M, Ratajczak P, Mizrachi M, Khamaysi Z, Behar D, Petronius D, Friedman V et al. 2004 Mutations in GALNT3, encoding a protein involved in O-linked glycosylation, cause familial tumoral calcinosis. Nature Genetics 36 579-581.

Urakawa I, Yamazaki Y, Shimada T, Iijima K, Hasegawa H, Okawa K, Fujita T, Fukumoto S \& Yamashita T 2006 Klotho converts canonical FGF receptor into a specific receptor for FGF23. Nature 444 770-774.

White KE, Carn G, Lorenz-Depiereux B, Benet-Pages A, Strom TM \& Econs MJ 2001 Autosomal-dominant hypophosphatemic rickets (ADHR) mutations stabilize FGF-23. Kidney International 60 2079-2086.

Yamashita T, Konishi M, Miyake A, Inui K \& Itoh N 2002 Fibroblast growth factor (FGF)-23 inhibits renal phosphate reabsorption by activation of the mitogen-activated protein kinase pathway. Journal of Biological Chemistry 277 28265-28270.

Yu X, Ibrahimi OA, Goetz R, Zhang F, Davis SI, Garringer HJ, Linhardt RJ, Ornitz DM, Mohammadi M \& White KE 2005 Analysis of the biochemical mechanisms for the endocrine actions of fibroblast growth factor-23. Endocrinology 146 4647-4656.

Received 26 February 2007

Accepted 5 April 2007

Made available online as an Accepted Preprint 11 April 2007 